\title{
EDITORIAL
}

\section{Sexual and gender-based violence}

\author{
Susan A. Bartels, MD, MPH \\ http://dx.doi.org/10.5588/pha.13.0040
}

C exual and gender-based violence (SGBV) continues to be a pervasive problem for women, men and children around the world. Many survivors are understandably concerned about the potential health sequelae of being sexually assaulted, primarily about unwanted pregnancies and transmission of sexually transmitted infections (STIs), including the human immunodeficiency virus (HIV). There has been much emphasis on prompt referral to medical care, as it has been shown that post-exposure prophylaxis (PEP) for STIs and HIV as well as emergency contraception are significantly more likely to be effective if taken within the first 72 hours following the assault. ${ }^{1}$

Historically, provision of post-assault care has been challenging in developing countries such as Kenya. ${ }^{2}$ Survivors may not be aware of the benefits of early medical care, post-assault medical protocols may not be in widespread use, confidentially may be poorly maintained and the required medicines may not be available at local clinics. Furthermore, there are often significant delays to seeking medical care, far beyond the recommended 72 hours, thus rendering prophylactic medical interventions almost useless. ${ }^{3,4}$

The article by Buard et al. in this issue of Public Health Action on the characteristics, management and outcomes of survivors of gender-based violence in Nairobi, describes the successful implementation of a comprehensive medical program for survivors of SGBV. ${ }^{5}$ The demographics of the sexual violence survivors presenting to their program were similar to those described by other providers in Kenya. ${ }^{6}$ In the program by Buard et al., many of the barriers to high quality post-assault medical care were overcome. Because it was an urban setting, lengthy travel times to access medical care were not a problem and, in fact, almost three quarters of the survivors sought medical attention within the recommended 72 hours. Being open $24 \mathrm{~h}$ per day, 7 days per week was likely important in allowing survivors to access medical services promptly. Furthermore, the fact that the clinic was well established, having run for 5 consecutive years, likely contributed to it being well known within the community.

Within the SGBV program offered by Buard et al., there was good uptake of HIV PEP, prophylactic antibiotics and emergency contraception, similar to reports by others. ${ }^{6}$ Although the attrition rates for subsequent hepatitis B and tetanus vaccination were high, they are within the realm of what might be expected given the setting and context. The authors make reasonable recommendations for addressing this high attrition, including digital tracking or reminders using mobile phones.

Buard et al. are to be commended for the high quality medical services they are providing to survivors of SGBV in Nairobi, and their program should serve as a model for other programs in similar urban settings. In circumstances where a survivor has been violated (often by someone known to him/her) and in the context of a judicial system that often fails the survivor either by re-traumatization and/or by failure to bring the perpetrator to justice, it is important that the health care system do right by these individuals by offering the best possible protection for their current and future health.

\section{References}

1 Linden J. Care of the adult patient after sexual assault. N Engl J Med 2011; 365: 834-841.

2 Kilonzo N, Theobald S, Nyamato E, et al. Delivering post-rape care services: Kenya's experience in developing integrated services. Bull World Health Organ 2009; 87: 555-559.

3 Amowitz L, Reis C, Hare Lyons K, et al. Prevalence of war-related sexual violence and other human rights abuses among internally displaced persons in Sierra Leone. JAMA 2002; 287: 513.

4 Bartels S, Scott J, Leaning J, et al. Demographics and care seeking behaviors of sexual violence survivors in South Kivu Province, Democratic Republic of Congo. Disaster Med Public Health Prep 2012; 6: 393-401.

5 Buard V, Van den Bergh R, Tayler-Smith K, et al. Characteristics, medical management and outcomes of survivors of sexual gender-based violence, Nairobi, Kenya. Public Health Action 2013; 3: 109-112.

6 Ranney M, Rennert-May E, Spitzer R, Chitai M, Mamlin S, Mabeya $\mathrm{H}$. A novel ED-based sexual assault centre in western Kenya: description of patients and analysis of treatment patterns. Emerg Med J 2011; 28: 927-931.
AFFILIATIONS

Faculty, Harvard Humanitarian Initiative, Cambridge, Massachusetts, USA Beth Israel Deaconess Medical Center, Boston, Massachusetts, USA

CORRESPONDENCE e-mail: sbartels@bidmc. harvard.edu
Public Health Action (PHA) The voice for operational research. Published by The Union (www.theunion.org), PHA provides a platform to fulfil its mission, 'Health solutions for the poor'. PHA publishes high-quality scientific research that provides new knowledge to improve the accessibility, equity, quality and efficiency of health systems and services.
e-ISSN 2220-8372

Editor-in-Chief: Donald A Enarson, MD, Canada

Contact: pha@theunion.org

PHA website: http://www.theunion.org/index.php/en/journals/pha Article submission: http://mc.manuscriptcentral.com/pha 